\title{
The Absorptive Capacity and Innovation in Jordanian Universities
}

\author{
Ayman Jarrar ${ }^{1}$ \\ ${ }^{1}$ World Islamic Science \& Education University, Jordan \\ Correspondence: Ayman Jarrar, World Islamic Science \& Education University, Jordan.
}

Received: November 9, 2021

Accepted: November 29, 2021

Online Published: January 4, 2022

doi:10.5539/mas.v16n1p22

URL: https://doi.org/10.5539/mas.v16n1p22

\begin{abstract}
Organizational transformation is a high-risk and difficult activity that all institutions must undertake. The objective of this article is to examine how businesses develop and utilize ACAP to aid with transformation. We examine how realized absorptive capacity in terms of transformation and exploitation capability directly affects organizational change and how process innovation practises act as an effective mechanism for connecting transformation and exploitation capability with organizational change, using a dynamic capability perspective and a'resourcing' synergy perspective. To differentiate ourselves, we focus on both an evolving organizational structure and an emerging economy context in this research. The findings and discussion that follow on how process innovation strategies might help colleges become more entrepreneurial will interest university administrators and lawmakers.
\end{abstract}

Keywords: absorptive capacity, innovation, leadership, higher education, Jordan

\section{Introduction}

Due to the dynamic and uncertain nature of the business world, organizations must constantly create new capabilities and invent new services and processes (Da Costa, Camargo, Toaldo, \& Didonet, 2018). Academics, policymakers, and business leaders must collaborate to boost organizational innovation, which has long been viewed as a critical factor in business growth and economic development (Haneda \& Ito, 2018). Competitive pressures sparked organizational innovation (Haneda \& Ito, 2018; Da Costa et al., 2018). Additionally, information is the primary catalyst for organizational innovation (Da Costa et al., 2018; Kim, Kumar \& Kumar, 2012).

Organizational innovation is a term that refers to novel ways of utilizing talents, experience, and resources to enhance the value of products and services offered to customers (Kim et al., 2012; Xie, Zou, \& Qi, 2018). Organizational innovation is founded on the recognition of potential markets and commercial opportunities. Additionally, it gathers new market and technology knowledge from the environment to translate and integrate it into internal processes to stay one step ahead of competitors (Zhang, Zhao, \& Lyles, 2018). The organization's ability to acquire and incorporate both codified explicit and tacit knowledge will be crucial in future product/service development (Xie et al., 2018; Zhang, Rong, \& Ji, 2019).

The absorptive capacity (ACAP) is a word that has been used in the literature to refer to the capacity for direct knowledge absorption (Zhang et al., 2018). ACAP refers to a firm's ability to recognize the value of new, external information, integrate it, and use it for commercial purposes (Cohen \& Levinthal, 1990, p. 128). There is a substantial amount of work on ACAP's applicability in various contexts, including organizational innovation (e.g., Cohen \& Levinthal, 1990; Zhang et al., 2019). ACAP is positively associated with relevant data kept by firms, enabling them to analyze signals for progress and improvement properly. ACAP, on the other hand, assists businesses in identifying any new information they require from the outside world and adapting and integrating it with existing internal knowledge (Albort-Morant, Leal-Rodrguez, \& De Marchi, 2018).

Numerous critical elements of organizational culture include a varied workforce, a proclivity for innovation, and an ability to adapt to change (Zhang et al., 2019). According to these ideas, culture significantly impacts organizational outcomes, especially in intercultural settings when teamwork and negotiation are difficult. Harmony among team members will aid in realizing the vision (Michailova and Ott, 2017). Cultural diversity contributes to happiness by sustaining superior learning and facilitating dramatic shifts in overall performance and achievement (Zhang et al., 2019). 
Strategic leadership has always been inextricably related to the firm's culture and employee attitudes, often in a positive way. More precisely, the effect of leadership on employee happiness has been well established throughout corporate history (Al-Sada, Al-Esmael, \& Faisal, 2017). Additionally, in comparison to all other leadership theories, the Leadership Styles Theory, which encompasses transformational leadership, has garnered the greatest attention in the literature to date (Sirin, Aydin, \& Bilir, 2018).

This is because transformational leadership is believed to inspire followers and empower them to think beyond their aims and interests to accomplish greater corporate, national, and global goals (Al-Sada et al., 2017).

Jordan's universities are a major economic engine. Due to Jordan's small economy and rising competition among Jordanian institutions, authorities have been forced to prioritize developing their expertise, resources, and capacity to respond to various environmental concerns.

The main objective of this study is to study the relationship between absorptive capacity and innovation in Jordanian Universities.

\subsection{Study Objectives and Importance}

This study will be a first in Jordan in that it will analyze the same subject up to the researcher's knowledge boundaries. As a result, it will enrich Jordan's academic work by providing a baseline for future research. It will also contribute to the literature on strategic management by determining whether absorptive capacity significantly predicts a university's ability to innovate. What role do corporate culture and strategic leadership play in establishing and enhancing this impact? As stated previously, this study examines Jordanian universities' absorptive capacity and innovation, taking into account the mediating roles of strategic leadership and the moderating effect of organizational culture.

\section{Literature Review}

Nusair's (2013) study examined the organizational climate's effect on innovation and job performance in Jordanian commercial banks. The study defined three characteristics of innovation: corporate culture, leadership, and team climate. The study employed a probability random sample methodology and collected data from five commercial banks in Amman, Jordan's capital. The study sampled 200 employees with sufficient field experience. Additionally, they administered a questionnaire. The data were examined using both descriptive and multiple regression techniques. The study discovered that the innovation climate affects job performance in Jordan's commercial banks. Additionally, the findings demonstrate the effect of the environment on innovation constructs (organizational culture for innovation, leadership for innovation, and team climate innovation).

Al Ahmad et al. (2019) conducted a study to determine the influence of transformational leadership on innovation, as assessed by product and process innovation. The study employed both a quantitative and an explanatory approach in its methodology. It analyzed the data using Structural Equations Modeling (SEM) in AMOS 20. The administration of a questionnaire gathered the data for this study to a stratified sample of 310 workers from 27 banks in Lebanon. The outcomes of the study indicate that transformational leadership has an effect on innovation in the banking sector.

Organizational transformation is a high-risk and difficult activity that all institutions must undertake. This article aims to examine how businesses develop and deploy capabilities to aid in their transformation. We examine how realized absorptive capacity in transformation and exploitation capability directly affects organizational change and how process innovation practices act as an effective mechanism for connecting transformation and exploitation capability with organizational change, using a dynamic capability perspective and resourcing synergy perspective. To differentiate ourselves, Zhang, Wang, and O'Kane (2019) focus on both an emerging organizational structure and an emerging economic context in our research. A questionnaire survey of 316 academics from Malaysian entrepreneurial universities discovered that transformation and exploitation competence are facilitators of organizational change.

On the other hand, process innovation practises mediating the relationship between transformation capability and organizational change completely, whereas process innovation practises mediating the relationship between exploitation capability and organizational change only partially. The findings contribute to the dynamic capability perspective on organizational change and absorptive capacity by highlighting the importance of integrating organizational transformation and exploitation capability with process innovation techniques in a variety of ways to facilitate organizational change. The findings and discussion that follow on how process innovation strategies might help colleges become more entrepreneurial will interest university administrators and lawmakers. 
Popescu, Ceptureanu, Alexandru, and Ceptureanu (2019) examine the links between absorptive capacity, organizational innovation and performance, and information technology in the context of Romanian SMEs (SMEs). Alexandru and Ceptureanu (2019) conducted the first study in Romania on absorptive knowledge capacity and information technology concepts, using a large sample of 357 SMEs. The study's findings establish the impact of many aspects of absorptive knowledge capacity on the organizational innovation performance of SMEs from an information technology perspective, providing new theoretical and practical insights.

Zhang et al. (2019) examine the ACAP's mediating effect on the relationship between information systems and trust and product innovation. The assumptions used regression and bootstrapping analytic data techniques to analyze a sample of 276 manufacturing enterprises in China. The findings of the study indicate that trust and information systems have a beneficial effect on product innovation. Additionally, ACAP is completely responsible for the effects. Additionally, the ACAP has a substantial impact on product creation, amplified by trust and information systems. Finally, the study's findings imply that trust and information systems help to improve ACAP.

Huang et al. (2018) investigate the influence of organizational forgetfulness on the performance of innovation. Additionally, it examines the moderating effect of environmental turbulence on innovation performance and the mediating effect of organizational forgetting on innovation performance. This study employed exploratory factor analysis (EFA) and hierarchical regression analysis. It used a survey to perform research. 320 Chinese firms are included in the research population.

According to the study's findings, organizational forgetfulness has a major impact on organizations' innovation performance. Without the ACAP, organizational forgetting has little effect on the organization's innovative performance. Additionally, the ACAP's mediating action has a beneficial influence on environmental turbulence.

Naqshbandi and Tabche (2018) examined the influence of leadership on the ACAP, the organizational learning culture, and the consequences of open innovation. The study's data was gathered through interviews with managers from a variety of sectors in India. The study's findings indicate that empowering leaders resulted in improved open innovation outcomes through the intervention of organizational learning culture. Additionally, the study demonstrates a considerable impact on open innovation of the combination of corporate culture and absorptive capacity.

Zou et al. (2017) conducted a meta-analysis of 241 papers and concluded that ACAP is a significant predictor of organizational innovation and knowledge transfer. Unlike most theoretical discussions, the researchers discovered that the relationship between business size and ACAP is beneficial for small firms. Nonetheless, it is a negative link for larger organizations and that the company age-ACAP relationship is negative.

The study shows that common theoretical reasons for organizational innovation should be reconsidered, particularly concerning the causal concepts driving age and size. These findings compel scholars to reconsider common beliefs about businesses and their corporate design patterns.

This study differs from others in that it examines the mediating and moderating effects of transformational leadership and culture. Additionally, it focuses on Jordanian universities.

\section{Absorptive Capacity (ACAP)}

The acronym ACAP stands for "knowledge acquisition, assimilation, transformation, and exploitation of new knowledge by firms" (Cohen \& Levinthal, 1990; Zahra \& George, 2002). It enables businesses to acquire and then integrate new information. Furthermore, organizational capabilities allow businesses to dynamically integrate and leverage internal resources to satisfy changing market demands (Teece et al., 2014). As a result, companies with a high ACAP can use most of their organizational skills to manage issues and read the environment following their internal capabilities and resources. As a result, they will respond proactively to client needs and achieve a competitive edge through innovation (Zhang et al., 2019; Martnez-Sánchez, Vicente-Oliva, \& Pérez-Pérez, 2020).

Martinez-Sanchez et al., 2020 depicted three-dimensional absorption capabilities. They define the ACAP as "a firm's ability to profit from outside information through exploratory learning, transformative learning, and exploitative learning" in a more precise, learning process-oriented description. "Experimental learning is utilized to recognize and grasp new external knowledge, transformative learning to absorb superficial knowledge, and exploitative learning to use the embodied external knowledge," according to Cohen and Levinthal (1990). (Zhang et al., 2019; Martinez-Sanchez et al., 2019)

The importance of the absorptive capacity concept is well recognized, and it has become one of the most important issues in contemporary management study. It can be used in various industries and has been used to 
explain a variety of organizational issues. It is on this that Zahra and George (2002) founded their definitions (Martinez-Sanchez et al., 2020; Zahra \& George, 2002).

According to their empirical study, transformation is an integral component of absorptive capacity, and it is not captured in knowledge acquisition, knowledge assimilation, or knowledge exploitation. This supports the four-dimension definition of absorptive capacity presented by Zahra and George (2002).

Building on this foundation and their comprehensive literature review, Zahra \& George (2002) introduce an extended conceptualization of absorptive capacity (potential vs realized) and operationalize the construct along with four primary capabilities/dimensions: knowledge Acquisition: identifying and acquiring external knowledge that is valuable for current operations.

- Knowledge Assimilation: interpreting and understanding new knowledge.

- Knowledge Transformational: developing and refining assimilated knowledge to facilitate its combination with existing knowledge.

- Knowledge Exploitation: integrating acquired and transformed knowledge into operations). While knowledge acquisition and assimilation are argued to constitute the potential absorptive capacity of an organization, transformation and exploitation represent its realized absorptive capacity.

\section{ACAP Development}

Zahra and George classify absorptive capacity as a first-order (dynamic) capability (2002). As such, ACAP is considered to be a first-order (dynamic) capability. The ACAP architecture was created to assist organizations in comprehending their adaptation to changing environmental situations. As a result, organizational learning theory and systems theory have aided in our current understanding of the phenomenon of absorptive capacity (Martinez-Sanchez et al., 2020; Naqshbandi and Tabche, 2018).

Zahra and George define absorptive capacity as a dynamic capability comprised of organizational routines and strategic processes that enables businesses to acquire, integrate, convert, and utilize the information to create value (Naqshbandi and Tabche, 2018). They distinguish between a firm's potential and actual capacity, dividing it into two categories of absorptive capacity. Knowledge acquisition and absorption are examples of potential absorptive capacity, whereas knowledge transformation and exploitation are examples of achieved absorptive capacity (Martinez-Sanchez et al., 2019; Zahra \& George 2002).

Assimilation refers to the processing and internalization of externally created information, whereas acquisition refers to discovering and acquiring external expertise vital to a business's operations. The act of designing and implementing methods that enable a business to merge existing expertise with newly acquired and absorbed knowledge is referred to as transformation (Whitehead et al., 2016). Knowledge can be added to, subtracted from, or reinterpreted. Finally, exploitation refers to incorporating newly learned and converted information into the operations of a firm. The focus is on the processes that enable the refinement, extension, and leveraging of existing competencies and the development of new ones (Da Costa et al., 2018; Zahra \& George, 2002).

Zahra and George (2002) introduced the ACAP, distinguishing between two types of ACAP. Zahra and George (2002) use this phrase to provide a new perspective on previous absorptive capacity findings. Zahra and George (2002) define absorptive capacity as a dynamic capability that enables a business to achieve and maintain a competitive advantage through the integration of knowledge development and application. While Cohen and Levinthal (1990) place a premium on the externally obtained information, Zahra and George emphasize processes and "dynamic capacity for strategic transformation and adaptability through which companies build and apply new knowledge by altering previous knowledge" (2002: 198).

\section{Organizational Innovation}

Organizational innovation is a market-driven approach and a synthesis of market requirements and technology capabilities (Azar and Ciabuschi, 2017).

Organizational innovation is a broad concept that encompasses the genesis, development, and implementation of a unique opinion or behaviour within the adopting company. Ideas are turned into new goods or services, new process technologies, new organizational structures, or new managerial techniques during the organizational innovation process (Damanpour and Aravind, 2012; Azar and Ciabuschi, 2017).

Organizational innovation is not just about producing new products or services; it also brings them to market. Corporate design is defined as "the capacity to transmit human resource knowledge and integrate it in order to create new knowledge that results in a new product or process (Zaied, Louati, \& Affes., 2015)”. Additionally, Afzal, Sulong, Dutta, and Mansur (2018) defined organizational innovation as "the competitive advantage that 
qualified human resources can provide." Marketing expertise helps firms to compete based on product quality and organizational innovation."

\section{Innovation Typologies}

Numerous typologies of organizational innovation have been presented. As a result, management researchers have developed an interest in technical-organizational typology. According to the same source, technical innovation is described as "the implementation of a concept for a new product or service, or the introduction of new elements into an organization's manufacturing process or service operation." It refers to a broad division between a company's technological and administrative systems, the former of which has a greater impact on its operational systems and the latter of which has a greater impact on the company's management systems (Damanpour and Aravind, 2012).

The second aspect is organizational innovation, defined as "the development and implementation of a novel to cutting-edge management practise, method, structure, or technology to achieve organizational goals."

Crossan and Apaydin (2010) define innovation as "the creation or adoption, assimilation, and exploitation of novel value-added products, services, and markets; the renewal and expansion of products, services, and markets; the development of new manufacturing methods, and the establishment of new management systems." It is both a procedure and a product." Businesses frequently increase their innovative efforts to improve their performance and profitability, and such expansion needs the development of new strategies, such as managing it within organizations through the incorporation of such knowledge into various operations.

\section{Organizational Culture}

A company's culture defines its identity and character. The organizational culture comprises common values, beliefs, and assumptions about how people should behave and interact, how decisions should be made, and how work activities should be conducted. The history and surroundings of an organization and the individuals that manage and work for it all play a role in its culture. Effective leadership requires an understanding of organizational culture (Shahzad, Xiu, \& Shahbaz, 2017).

Leaders and managers who understand their culture will be more equipped to implement strategy and accomplish their objectives. Contrary to corporate culture, strategies are likely to encounter resistance and will be more difficult, if not impossible, to implement (Shahzad et al., 2017). In comparison, consistent methods will be easier to implement and more likely to succeed. Additionally, it is critical to understand an organization's existing culture prior to implementing changes (Shahzad et al., 2017).

It may take years for new hires to comprehend and absorb the culture fully, or it may occur quite quickly - the extent to which the organization has a healthy onboarding method will be crucial. However, in other instances, an influx of new employees can alter the established culture, particularly at the top level. In practice, while an organization may have an 'umbrella' culture outlining how things should be done and what is acceptable, subsidiary cultures might arise based on job roles or other allegiances. Inevitably, individuals experience and interpret culture subjectively based on their own beliefs and viewpoint on the organization. Certain facets may be more significant to some individuals than others, depending on their jobs (Sperber, 2017).

To understand an organization's culture, its written and unwritten rules should be examined alongside its people's relationships, values, and behaviours. This checklist begins by outlining some well-known approaches proposed by management theorists to classify organizational cultures, and these suggest the dimensions the policymaker should look at when assessing expressions of culture in a particular organization. Secondly, the key steps to follow and questions to ask to help to understand are presented (Sperber, 2017; Shahzad et al., 2017).

\section{Transformational Leadership}

Leadership is required to control and manage both companies and employees. The applicability of leadership styles is decided mostly by the industry in which they operate. On the other side, influential leaders understand how to motivate and boost their employees' motivation to the point of loyalty. The most well-known leadership styles are transformational, transactional, and laissez-faire (Northouse, 2018).

The concept of "leadership" is a wide one with numerous definitions in management literature. For example, management definitions differ according to the organization's classification and the extent to which the culture that inspires the leader, followers, and stakeholders motivates the leader, followers, and stakeholders (Avery, 2004).

They were reestablishing the principles. Stodgily described leadership as "the evolution of influencing the activities of a systematized group in their efforts toward goal formulation and achievement" in 1950, according 
to Azhar and Hassan (2014). In the 1970s, the authors defined leadership as "the act of leaders exerting influence over their followers."

Nanus (1992) defines transformational leadership as "the capacity to generate and articulate distinct visions that give meaning and purpose to an organization's activities." According to a subsequent study, activating the visionary leadership style contributes to creating an innovative culture shift by providing a rich vision that is tied to the organization's goals and external trends. Transformational leaders may successfully create anticipated visions while keeping their values and ethos in mind to motivate people to adhere to the vision.

\section{Discussion and Conclusion}

According to a prior study, organizational change is associated with resource conversion, use, and development of effective practices (e.g., Heyden et al., 2017; Teece, 2012). The purpose of this study is to substantiate these assumptions by examining the direct and indirect effects of realized absorptive ability on organizational change. The findings of this study, in particular, support the importance of transformation impacts and exploitation skills in influencing organizational change. The concept that process innovation practises completely mediates the relationship between transformation capability and organizational change and partially mediate the effects of exploitation capability on the organizational change also has a widespread agreement.

Finally, this study examines how RACAP's transformation and exploitation capabilities contribute to organizational change in entrepreneurial institutions via process innovation techniques. Our findings indicate that a company's realized absorptive capacity enables it to design process innovation strategies that facilitate organizational change. Additionally, it demonstrates that process innovation strategies effectively integrate transformation capability and organizational change but only partially integrate exploitation capability and organizational change.

Our research indicates that to effect organizational change, administrators of entrepreneurial universities in emerging economies should implement certain methods that enhance their ability to adapt and leverage valuable know-how, hence facilitating organizational transformation. Managers should also analyze the nature of their internal innovation systems, as this may impact their organizations' amount of external information. Additionally, our findings indicate that process innovation techniques may provide a practical framework for changing and utilizing external information to effect organizational change. As a result, after sufficient knowledge has been transformed and exploited, we advise university administrators to consider applying their expertise and resources to process innovation practices. Finally, university administrators must comprehend the numerous ways in which transformation and exploitation capabilities can assist businesses in adapting. Managers should ensure that process innovation strategies are included in the transformation capability creation process, as the benefits of transformation capability to organizational change are path-dependent. On the other hand, they can be used in conjunction with exploitation and process innovation methodologies, as exploitation capability benefits direct and indirect organizational transformation.

These findings contribute to our understanding of how process innovation practises identifying an entirely dependent path for transformation capability to contribute to organizational change while also developing a partially dependent path for exploitation capability to affect and directly facilitate organizational change. More broadly, this research advances our understanding of how organizational transformation may occur due to novel integrations of organizational skills and innovation channels, particularly among entrepreneurial institutions in a developing economy.

\section{Limitations and Future Research}

The main limitation of the study is the lack of literature in the universities in Jordan. The data and access was another limitation to consist an empirical paper.

Future research needs to consider the practical side and conduct data analysis. Future research also can consider the impact of COVID 19 on the innovation channels and ACAP.

\section{References}

Afzal, M. N. I., Sulong, R. S., Dutta, S., \& Mansur, K. (2018). An investigation on the triple helix model and national innovation systems: The case of Malaysia. Asian Journal of Innovation and Entrepreneurship, 3(3), 299-313.

Al Ahmad, S., Easa, N. F., \& Mostapha, N. (2019). The effect of transformational leadership on innovation: Evidence from Lebanese Banks. Retrieved from https://www.um.edu.mt/library/oar/handle/123456789/50811 
Albort-Morant, G., Leal-Rodríguez, A. L., \& De Marchi, V. (2018). Absorptive capacity and relationship learning mechanisms as complementary drivers of green innovation performance. Journal of Knowledge Management, 22(2), 432-452. https://doi.org/10.1108/JKM-07-2017-0310

Avery, G. C. (2004). Understanding leadership: Paradigms and cases. Sage.

Azar, G., \& Ciabuschi, F. (2017). Organizational innovation, technological innovation, and export performance: The effects of innovation radicalness and extensiveness. International Business Review, 26(2), 324-336. https://doi.org/10.1016/j.ibusrev.2016.09.002

Azhar, T., \& Hassan, T. (2014). Impact of leadership training on competitive advantage: a study on telecommunication industry of Pakistan. European Journal of Business and Management, 6(23), 209-215.

Camisón, C., \& Forés, B. (2010). Knowledge absorptive capacity: New insights for its conceptualization and measurement. Journal of Business Research, 63(7), 707-715. https://doi.org/10.1016/j.jbusres.2009.04.022

Cohen, W. M., \& Levinthal, D. A. (1990). Absorptive capacity: A new perspective on learning and innovation. Administrative science quarterly, 128-152.

Crossan, M. M., \& Apaydin, M. (2010). A multi-dimensional framework of organizational innovation: A systematic review of the literature. Journal of management studies, 47(6), 1154-1191. https://doi.org/10.1111/j.1467-6486.2009.00880.x

Damanpour, F., \& Aravind, D. (2012). Managerial innovation: Conceptions, processes, and antecedents. Management and organization review, 8(2), 423-454. https://doi.org/10.1111/j.1740-8784.2011.00233.x

Haneda, S., \& Ito, K. (2018). Organizational and human resource management and innovation: Which management practices are linked to product and/or process innovation? Research Policy, 47(1), 194-208. https://doi.org/10.1016/j.respol.2017.10.008

Kafetzopoulos, D., \& Psomas, E. (2015). The impact of innovation capability on the performance of manufacturing companies: The Greek case. Journal of Manufacturing Technology Management, 26(1), 104-130. https://doi.org/10.1108/JMTM-12-2012-0117

Kantabutra, S., \& Rungruang, P. (2013). Perceived vision-based leadership effects on staff satisfaction and commitment at a Thai energy provider. Asia-Pacific Journal of Business Administration, 5(2), 157-178. https://doi.org/10.1108/17574321311321621

Kantabutra, S., \& Saratun, M. (2011). Identifying vision realization factors at a Thai state enterprise. Management Research Review, 34(9), 996-1017. https://doi.org/10.1108/01409171111158965

Kanter, R. M. (1968). Commitment and social organization: A study of commitment mechanisms in utopian communities. American sociological review, 33(4), 499-517. https://doi.org/10.2307/2092438

Kim, D. Y., Kumar, V., \& Kumar, U. (2012). Relationship between quality management practices and innovation. Journal of operations management, 30(4), 295-315. https://doi.org/10.1016/j.jom.2012.02.003

Liu, X., Zhao, H., \& Zhao, X. (2018). Absorptive capacity and business performance: The mediating effects of innovation and mass customization. Industrial Management \& Data Systems, 118(9), 1787-1803. https://doi.org/10.1108/IMDS-09-2017-0416

Michailova, S., \& Ott, D. (2017, July). International experience and cultural intelligence development: A social learning framework. In 59th Annual Meeting of the Academy of International Business. Academy of International Business.

Nanus, B. (1992). Visionary Leadership: Creating a Compelling Sense of Direction for Your Organisation. Jossey-Bass Inc.

Naqshbandi, M. M., \& Tabche, I. (2018). The interplay of leadership, absorptive capacity, and organizational learning culture in open innovation: Testing a moderated mediation model. Technological Forecasting and Social Change, 133, 156-167. https://doi.org/10.1016/j.techfore.2018.03.017

Northouse, P. G. (2018). Leadership: Theory and practice. Sage publications.

Nusair, N., Ababneh, R., \& Bae, Y. K. (2012). The impact of transformational leadership style on innovation as perceived by public employees in Jordan. International Journal of Commerce and Management, 22(3), 182-201. https://doi.org/10.1108/10569211211260283

Nusair, T. T. (2013). The role of climate for innovation in job performance: Empirical evidence from commercial banks in Jordan. International Journal of Business and Social Science, 4(3). 
Nwachukwu, C., Chládková, H., \& Žufan, P. (2017). The relationship between entrepreneural orientation, entrepreneurial competencies, entrepreneurial leadership, and firm performance: a proposed model.

Popescu, D. I., Ceptureanu, S. I., Alexandru, A., \& Ceptureanu, E. G. (2019). Relationships between Knowledge Absorptive Capacity, Innovation Performance and Information Technology. Case Study: The Romanian Creative Industries SMEs. Studies in Informatics and Control, 28(4), 463-475. https://doi.org/10.24846/v28i4y201910

Ruel, H., Rowlands, H., \& Njoku, E. (2020). Digital business strategizing: the role of leadership and organizational learning. Competitiveness Review, 31(1), 145-161. https://doi.org/10.1108/CR-11-2019-0109

Sánchez-Báez, E. A., Fernández-Serrano, J., \& Romero, I. (2020). Organizational culture and innovation in small businesses in Paraguay. Regional Science Policy \& Practice, 12(2), 233-247.

Sirin, Y. E., Aydin, Ö., \& Bilir, F. P. (2018). Transformational-Transactional Leadership and Organizational Cynicism Perception: Physical Education and Sport Teachers Sample. Universal Journal of Educational Research, 6(9), 2008-2018. https://doi.org/10.13189/ujer.2018.060920

Sperber, S. C. (2017). THE TOP MANAGERS' IMPACT ON OPENING THE ORGANIZATIONAL CULTURE TO INNOVATION. International Journal of Innovation Management, 21(2), 1750014. https://doi.org/10.1142/S1363919617500141

Tetik, S. (2020). Strategic Leadership in Perspective of Industry 4.0. In Akkaya, B. (Ed.), Agile Business Leadership Methods for Industry 4.0 (pp. 193-207). Emerald Publishing Limited. https://doi.org/10.1108/978-1-80043-380-920201012

Whitehead, K. K., Zacharia, Z. G., \& Prater, E. L. (2016). Absorptive capacity versus distributive capability. International Journal of Operations \& Production Management, 36(10), 1308-1332. https://doi.org/10.1108/IJOPM-06-2015-0379

Xie, X., Zou, H., \& Qi, G. (2018). Knowledge absorptive capacity and innovation performance in high-tech companies: A multi-mediating analysis. Journal of Business Research, 88, 289-297. https://doi.org/10.1016/j.jbusres.2018.01.019

Zahra, S. A., \& George, G. (2002). The net-enabled business innovation cycle and the evolution of dynamic capabilities. Information systems research, 13(2), 147-150. https://doi.org/10.1287/isre.13.2.147.90

Zaied, R. M. B., Louati, H., \& Affes, H. (2015). The relationship between organizational innovations, internal sources of knowledge and organizational performance. International Journal of Managing Value and Supply Chains, 6(1), 53-67. https://doi.org/10.5121/ijmvsc.2015.6105

Zhang, D., Rong, Z., \& Ji, Q. (2019). Green innovation and firm performance: evidence from listed companies in China. Resources, Conservation and Recycling, 144, 48-55. https://doi.org/10.1016/j.resconrec.2019.01.023

Zhang, J. A., Wang, Z., \& O'Kane, C. (2019). Realized absorptive capacity and entrepreneurial universities' organizational change: the role of process innovation practices. $R \& D$ Management, 49(5), 716-733. https://doi.org/10.1111/radm.12366

\section{Copyrights}

Copyright for this article is retained by the author(s), with first publication rights granted to the journal.

This is an open-access article distributed under the terms and conditions of the Creative Commons Attribution license (http://creativecommons.org/licenses/by/4.0/). 